\title{
Porosity effects of natural latex (Hevea brasiliensis) on release of compounds for biomedical applications
}

M. C. R. Miranda, F. G. Prezotti, F. A. Borges, N. R. Barros, B. S. F. Cury, R. D. Herculano \& E. M. Cilli

To cite this article: M. C. R. Miranda, F. G. Prezotti, F. A. Borges, N. R. Barros, B. S. F. Cury, R. D. Herculano \& E. M. Cilli (2017) Porosity effects of natural latex (Hevea brasiliensis) on release of compounds for biomedical applications, Journal of Biomaterials Science, Polymer Edition, 28:18, 2117-2130, DOI: 10.1080/09205063.2017.1377024

To link to this article: https://doi.org/10.1080/09205063.2017.1377024

Accepted author version posted online: 06

Sep 2017.

Published online: 17 Sep 2017.

Submit your article to this journal $\pi$

Џll Article views: 192

View Crossmark data 5

Citing articles: 4 View citing articles 지 


\title{
Porosity effects of natural latex (Hevea brasiliensis) on release of compounds for biomedical applications
}

\author{
M. C. R. Miranda a,b, F. G. Prezottic, F. A. Borges ${ }^{b}$, N. R. Barros ${ }^{a, b}$ (D) B. S. F. Cury', \\ R. D. Herculano ${ }^{b}$ and E. M. Cillia
}

aDepartment of Biochemistry and Chemical Technology, Institute of Chemistry, UNESP - Universidade Estadual Paulista, Araraquara, Brazil; ${ }^{b}$ Bioprocess and Biotechnology Department - FCF, UNESP - Universidade Estadual Paulista, Araraquara, Brazil; 'Drugs and Pharmaceuticals Department - FCF, UNESP - Universidade Estadual Paulista, Araraquara, Brazil

\begin{abstract}
Natural rubber latex biomedical (NRLb) obtained from the rubber tree Hevea brasiliensis has shown great potential in biomedicine and biomaterial applications. NRLb has been utilized as a physical barrier against infectious agents and in the controlled release of drugs and extracts. In the present work, NRLb was polymerized in a lyophilizer using different volumes of water to control the resultant membrane porosity and characterized regarding the surface morphology, water vapour permeability (WVP), mechanical properties, haemolytic activity and cytotoxicity. The release of bovine serum albumin protein from the latex membranes was evaluated. Drug release rates increased with porosity and membranes were able to control protein release up to $12 \mathrm{~h}$. In addition, WVP increased with the quantity of pores. The cell viability observed for the porous membrane was higher than that noted for conventional membranes. In summary, the porosity control of natural latex membranes can be used to modulate properties and make them suitable for biomedical applications, such as wound dressings, modulated gas-exchange membranes and controlled drug delivery systems.
\end{abstract}

\section{ARTICLE HISTORY}

Received 28 June 2017

Accepted 5 September 2017

\section{KEYWORDS}

Lyophilized membrane; natural rubber latex; drug delivery; biomaterial; thermally Induced Phase Separation (TIPS)

\section{Introduction}

Natural rubber latex (NRL) is obtained from the Brazilian rubber tree Hevea brasiliensis. NRL is a colloidal system comprising $50 \%$ water, $30-45 \%$ rubber particles (cis-1,4-polyisoprene), and $4-5 \%$ non-rubber constituents (such as proteins, lipids, and carbohydrates) [1]. The non-rubber components play an important role in stabilizing the latex particles and in contributing to the outstanding properties of NRL [2]. To obtain latex serum and latexbased membranes, conventional protocols have employed chemicals compounds, such as sulphur and carbamates [3]. However, the materials obtained by these methods have been associated with allergic reactions and cytotoxicity. As an alternative to the materials prepared via conventional methods, natural rubber latex biomedical (NRLb) materials have been used for biomedical applications. NRLb has been shown to be biocompatible and can both 
stimulate angiogenesis and the formation of extracellular matrices and promote cellular adhesion and tissue replacement and repair [4].

Researchers have used NRLb as a passive biomembrane for bone repair. In this application, the latex biomembrane is applied to bone fractures to prevent the migration of epithelial cells and connective tissue and to facilitate the migration of regenerative cells [5]. Other biomedical applications include the treatment of pressure ulcers [6] and diabetic ulcers [7], among others [8]. This natural latex has also been used to stimulate neovascularization and organized tissue growth in different organs and tissues and has been shown to be an innocuous material that is not rejected by the body. These characteristics make this latex an excellent candidate for developing solid matrices as delivery systems. Pharmaceutical studies on NRLb have specifically shown promising results for its use as a matrix as a delivery system for metronidazole, nicotine, Stryphnodendron sp. (S. barbatiman in particular), extracts from Casearia sylvestris, nanoparticles, diclofenac, and bovine serum albumin (BSA) [9].

Despite the many applications of NRLb, the effect of porosity on membrane properties has not been completely evaluated. Here, we developed a new method to produce latex membranes via lyophilisation, which allows control of membrane porosity through the addition of different volumes of water. This ability to control the pore structure enabled us to control drug release and gas diffusion through the membrane.

\section{Materials and methods}

\subsection{Production of NRL membrane}

The NRL used in the present study was extracted by BDF Rubber Latex Co., Ltd. (a producer and distributor of concentrated rubber latex), Guarantã, Brazil. The latex, which was extracted from $H$. brasiliensis, consisted of a mixture of two clones (RRIM 600 and PB 235). After extraction, ammonia was used to maintain the latex in liquid form. It is the most used anticoagulant and displays biocidal effects. The use of ammonia sustains the $\mathrm{pH}$ slightly alkaline and maintains the stability of the latex (anionic) [10,11]. This material was centrifuged at 19,000 rpm to reduce the amount of proteins in the natural latex that can cause allergic reactions $[9,12]$. The natural latex dispersion consisted of $0.22 \%$ proteins; $27 \%$ of these proteins were removed during the deproteinization process, yielding an NRLb membrane with $0.16 \%$ proteins [13]. The proteins responsible for allergic reactions have a molecular weight of about $14 \mathrm{kDa}$ which are separated by centrifugation [14].

Membranes were prepared using the casting method. For this purpose, the latex $(0.5 \mathrm{~mL})$ was diluted with different volumes of deionized water $(1: 1,2: 1,3: 1,4: 1$ or 5:1 water:latex ratio). One control sample was also prepared without adding water. After homogenization, the diluted latex dispersion were deposited on circular glass plates (22.3 $\mathrm{mm}$ in diameter), coated with liquid nitrogen for $2 \mathrm{~min}$ and lyophilized for $24 \mathrm{~h}$. The samples were labelled according to their water:latex ratio, as follows: M_0 (without addition of water), M_1 (1:1), M_2 (2:1), M_3 (3:1), M_4 (4:1) and M_5 (5:1). A conventional membrane (CM_37 $\left.{ }^{\circ} \mathrm{C}\right)$ was also prepared by pouring the latex dispersion onto a circular glass plate and polymerizing at $37^{\circ} \mathrm{C}$ for $48 \mathrm{~h}$ [9]. Polymerization of the latex occurs instantaneously upon evaporation of the water at $37^{\circ} \mathrm{C}$, either through liophilization [15].

For the release studies, $1 \mathrm{mg}$ BSA was added in $0.5 \mathrm{~mL}$ of latex dispersion and different volumes of deionized water before polymerization [16]. 


\subsection{Scanning electron microscopy}

The surface morphology of the NRLb membranes was evaluated by scanning electron microscopy (SEM; Zeiss EVO 50, Germany) at an accelerating voltage of $20 \mathrm{kV}$ and a take-off angle of $35^{\circ}$.

\subsection{Water vapour permeability}

Membrane water vapour permeability (WVP) was evaluated using the adapted gravimetric method proposed by Akhgari et al. [17], Prezotti et al. [18]. Circular sections of the membranes were carefully affixed to the top of permeability cups (70 $\mathrm{mm}$ tall, tinted glass bottles) closed with perforated lids (7 mm-radius holes) and containing $10 \mathrm{~mL}$ of purified water (100\% relative humidity). An empty cup was used as control. Each sealed permeability cup was accurately weighted $( \pm 0.0001 \mathrm{~g})$ before being placed in a desiccator containing silica gel ( $0 \%$ relative humidity) under vacuum. The permeability cups were weighed every $24 \mathrm{~h}$ for five days to evaluate mass loss (g) vs. time (h). All membranes were tested in triplicate and the WVP was calculated using the following equation:

$$
\mathrm{WVP}=\frac{w x}{t A P_{0}\left(\mathrm{RH}_{1}-\mathrm{RH}_{2}\right)}
$$

where WVP is the water vapour permeability $\left(\mathrm{g} \mathrm{mm} / \mathrm{m}^{2} \mathrm{~h} \mathrm{kPa}\right) ; w / t(\mathrm{~g} / \mathrm{h})$ is the water vapour transmission flux, i.e. the slope of the curve for mass loss vs. time $(\mathrm{g} / \mathrm{h}) ; x$ is the membrane thickness ( $\mathrm{mm}) ; A$ is the area of the membrane exposed to the permeate $\left(\mathrm{m}^{2}\right)$; $P_{0}$ is the vapour pressure of pure water $\left(3.159 \mathrm{kPa}\right.$ at $\left.25^{\circ} \mathrm{C}\right)$; and $\left(\mathrm{RH}_{1}-\mathrm{RH}_{2}\right)$ is the relative humidity gradient [17].

\subsection{Mechanical properties}

The mechanical properties (such as the puncture strength (PS) and elongation at break $\left.\left(E_{\mathrm{b}}\right)\right)$ of the membranes were evaluated using a texture analyser (TA-TX Plus, Stable Micro Systems, Ltd., UK) using a compression test mode. For this purpose, sections of the membranes were fixed between circular plates of a film support rig (with a $10 \mathrm{~mm}$-diameter film holder hole). The puncture probe used had a spherical ball tip (5 $\mathrm{mm}$ in diameter; code SMS $\mathrm{P} / 5 \mathrm{~S})$. Graphs of force $(\mathrm{N})$ vs. distance $(\mathrm{mm})$ were recorded until membrane rupture using the following parameters: a pre-test speed of $2 \mathrm{~mm} / \mathrm{s}$, a test speed of $1 \mathrm{~mm} / \mathrm{s}$, a trigger force of $0.98 \mathrm{~N}$ and a break sensitivity of $0.0049 \mathrm{~N}$. The mechanical properties were calculated according to the following equations [19]:

$$
\mathrm{PS}=\frac{F_{\text {max }}}{A_{\mathrm{CS}}}
$$

where PS $(\mathrm{MPa})$ is the puncture strength, $F_{\max }(\mathrm{N})$ is the maximum force exerted to break the membrane and $A_{\mathrm{CS}}\left(\mathrm{m}^{2}\right)$ is the cross-sectional area of the membrane exposed between the circular plates of the film support rig $\left(A_{\mathrm{CS}}=2 r \delta\right.$, where $r$ is the radius of the hole and $\delta$ is the membrane thickness), and

$$
E_{\mathrm{b}}=\frac{\sqrt{r^{2}+d^{2}}-r}{.} \times 100
$$


where $E_{\mathrm{b}}(\%)$ is the percentage of elongation at break, $r(\mathrm{~mm})$ is the radius of the membrane exposed between the circular plates of the film support rig and $d(\mathrm{~mm})$ is the distance representing the displacement of the probe from the contact point with the membrane until rupture. All membranes were tested in triplicate.

\subsection{Release assay}

BSA was used as a model drug to evaluate the release profile from the porous membrane and its efficiency compared to the conventional membrane.

The release assay was performed in $10 \mathrm{~mL}$ of deionized water containing a BSAincorporating latex membrane and maintained under constant agitation at $110 \mathrm{rpm}$ and a controlled temperature of $37^{\circ} \mathrm{C}$. Briefly, $30 \mu \mathrm{L}$ aliquots were removed at pre-determined intervals until the release profile stabilized. The samples were analysed using highperformance liquid chromatography (HPLC) (Shimadzu model LC-10A/C-47A, Japan) in analytic mode under the following conditions: Solvents A $(0.045 \%$ trifluoroacetic acid (TFA) in $\left.\mathrm{H}_{2} \mathrm{O}\right)$ and $\mathrm{B}(0.036 \%$ TFA in acetonitrile $(\mathrm{ACN}))$ in a 5-95\% (v/v) Solvent B gradient over $30 \mathrm{~min}$ at a flow rate $1 \mathrm{~mL} / \mathrm{min}$ in a $\mathrm{C}_{9}$ KROMASIL $(15.0 \times 0.46 \mathrm{~cm}$ column $)$ and UV detection at $220 \mathrm{~nm}$.

Characteristic peak areas were compared with those of controls ( $1 \mathrm{mg} / \mathrm{mL} \mathrm{BSA})$ to calculate the masses of released proteins.

\subsection{Haemolytic assay}

The interactions of the NRLb membrane produced using the conventional method at $37^{\circ} \mathrm{C}$ $\left(\mathrm{CM} \_37^{\circ} \mathrm{C}\right)$ and the porous membranes produced via the proposed method (M_1, M_3, and M_5) with red blood cells were studied using haemolytic activity assays. Specifically, the components released by the latex membranes were evaluated based on damage to the membranes of red blood cells (NEW PROV, code: 1189, Paraná, Brazil).

The haemolytic activity of the materials (CM_37 ${ }^{\circ} \mathrm{C}, \mathrm{M} \_1, \mathrm{M} \_3$ and $\left.\mathrm{M} \_5\right)$ was investigated according to a protocol described by Onuma et al. [20], with modifications, including use of sheep red blood erythrocytes.

The different membranes were incubated in phosphate-buffered saline (PBS) at $\mathrm{pH} 7.4$ for $24 \mathrm{~h}$ at $0.2 \mathrm{~g} / \mathrm{mL}$. The eluate solutions from the membrane incubations were used to determine the haemolysis percentage.

The membrane samples were subsequently incubated in $50 \mu \mathrm{L}$ of extract and $50 \mu \mathrm{L}$ of erythrocyte solution at $37^{\circ} \mathrm{C}$ for $1 \mathrm{~h}$. Subsequently, the tubes were centrifuged at $3000 \mathrm{rpm}$ for $3 \mathrm{~min}$, and $50 \mu \mathrm{L}$ aliquots of supernatant were pipetted into 96-well microplates. Absorbance measurements at $540 \mathrm{~nm}$ were determined using a microplate reader (BioTek, Epoch model). A $100 \%$ haemolysis value was determined using $50 \mu \mathrm{L}$ of PBS with $100 \mu \mathrm{L}$ of Triton X-100 at $1 \%(\mathrm{v} / \mathrm{v})$, and a $0 \%$ haemolysis value was obtained using $100 \mu \mathrm{L}$ of buffer. The experiments were performed in triplicate.

\subsection{Cell culture}

MC3T3 E-1 subclone 14 cells were acquired from the Rio de Janeiro Cell Bank (NCE/ UFRJ, Brazil). The cells were grown in complete growth medium comprising minimum 
essential Eagle's medium (Alpha-MEM) (Thermo Fisher, USA), 10\% foetal bovine serum (FBS; LGC Biotechnology, Brazil) and antibiotic-antimycotic $(100 \mu \mathrm{g} / \mathrm{mL}$ penicillin $\mathrm{G}, 100$ $\mathrm{U} / \mathrm{mL}$ streptomycin sulphate, and $0.25 \mu \mathrm{g} / \mathrm{mL}$ amphotericin B; Sigma-Aldrich). The cells were dissociated with TrypLE enzyme (Thermo Fisher, USA) following washing with PBS. The cultures were incubated in a humidified atmosphere containing $5 \% \mathrm{CO}_{2}$ at $37^{\circ} \mathrm{C}$.

\subsubsection{Cytotoxicity assay}

The cytotoxicity assay was performed according to the International Standard Organization (ISO) 10993, parts 5 and 12. Membranes, negative control (cell culture polystyrene), and positive control (PC, latex glove) were incubated in complete growth medium at $0.2 \mathrm{~g} / \mathrm{mL}$ ( $100 \%$ eluate) for $24 \mathrm{~h}$ at $37^{\circ} \mathrm{C}$ in $5 \% \mathrm{CO}_{2}$. The eluate (complete growth medium with the leachable extracted substances) was applied at concentrations of 100, 80, 60 and 40\% (diluted with complete growth medium). The aim of this study was to evaluate the cytotoxicity of soluble latex components (proteins, carbohydrates and others). A latex glove (LG) was used for comparison.

Cells were seeded at a density of $10^{4}$ cells/well and incubated overnight. The culture media were then replaced with the above-described test solutions, followed by incubation for $24 \mathrm{~h}$. All cytotoxicity assays were performed under sterile conditions. The evaluation of cytotoxicity was performed using MTT (3-(4,5-dimethylthiazol-2-yl)-2,5-diphenyltetrazoliumbromide; Sigma-Aldrich). Briefly, the eluate samples were removed, $100 \mu \mathrm{L}$ of fresh culture medium was added along with $10 \mu \mathrm{L}$ of MTT $(5 \mathrm{mg} / \mathrm{mL})$, and the cells were incubated for $4 \mathrm{~h}$ at $37^{\circ} \mathrm{C}$ and $5 \% \mathrm{CO}_{2}$. The supernatants were then removed, and the formed formazan crystals were solubilized with $100 \mu \mathrm{L}$ of DMSO. Absorbance measurements were recorded at $570 \mathrm{~nm}$ with a reference wavelength at $690 \mathrm{~nm}$. Cell viability is expressed as a percentage relative to the negative control, and the results are expressed as means \pm standard errors. The results were statistically analysed by one-way ANOVA (Bonferroni post hoc test, $n=3$; significance was considered for $p<0.05$ ).

\section{Results and discussion}

In this work, the NRLb membranes were prepared without using such cross-linking agents as carbamates and sulphur; these compounds are known to cause allergic and cytotoxic reactions [21]. The membranes were polymerized in a lyophilizer, and different volumes of water were added to control the porosity. The porosity and the size of the pores increased with the increase in the water volume used during membranes preparation.

Westall et al. [22] evaluated the molecular weight distribution (MWD) of NRL. The distributions showed bimodal distribution with fractions ranging from 70,000 g/mol to 2,500,000 g/mol. Kovuttikulrangsie and Tanaka [23] showed that the average molecular weight (MW) of natural latex from virgin trees ranged from about 330,000 to 1,200,000 g/ mol. The polymers from tree clones of 25 -year-old had average molecular weight (MW) between 670,000 and 3,000,000 g/mol. Kovuttikulrangsie and Sakdapipanich [24] showed that the MW and MWD of natural latex depended on the age and clone of rubber tree. The authors observed a unimodal distribution with a small variation in MW and narrow MWD of different clones. The MW reduction of a polymer occurs under the influence of environmental factors such as heat, light or chemicals such as acids, alkalis and some salts. Head and Lauter [25] observed MW degradation of natural polymers using ultrasonication, 
while Chae et al. [26] evaluated the influence of MW on oral absorption of water-soluble chitosans. In these studies, it was not observed that the water addition in the natural latex solution affected the MW and MWD.

\subsection{Scanning electron microscopy}

The influence of the addition of water to the latex dispersion before lyophilization was evaluated by SEM. Photomicrographs (Figure 1) show that the number of pores was directly proportional to the volume of water added during the membrane formation process. An increased porosity was most evident for sample M_5, which had the highest water:latex ratio (5:1). The membrane obtained without adding water (M_0) showed small pores, likely formed from the water molecules inherent within the latex. The membrane prepared using the conventional method $\left(\mathrm{CM} \_37^{\circ} \mathrm{C}\right)$ was notably lacking pores.

These results indicate that the thermally induced phase separation method (TIPS) used by Herculano et al. [15], Lloyd et al. [27] was also efficient using the lyophilizer. Freezing of the water contained or added to the latex and subsequent sublimation leads to pore formation in the places where the water crystallized (Figure 2).

Issarayungyuen et al. [28] also have developed highly porous latex using the foaming agent ammonium oleate, which enables incorporation of air into the latex when stirred vigorously. Our work presents an advantageous method that does not require the use of such foaming agents.

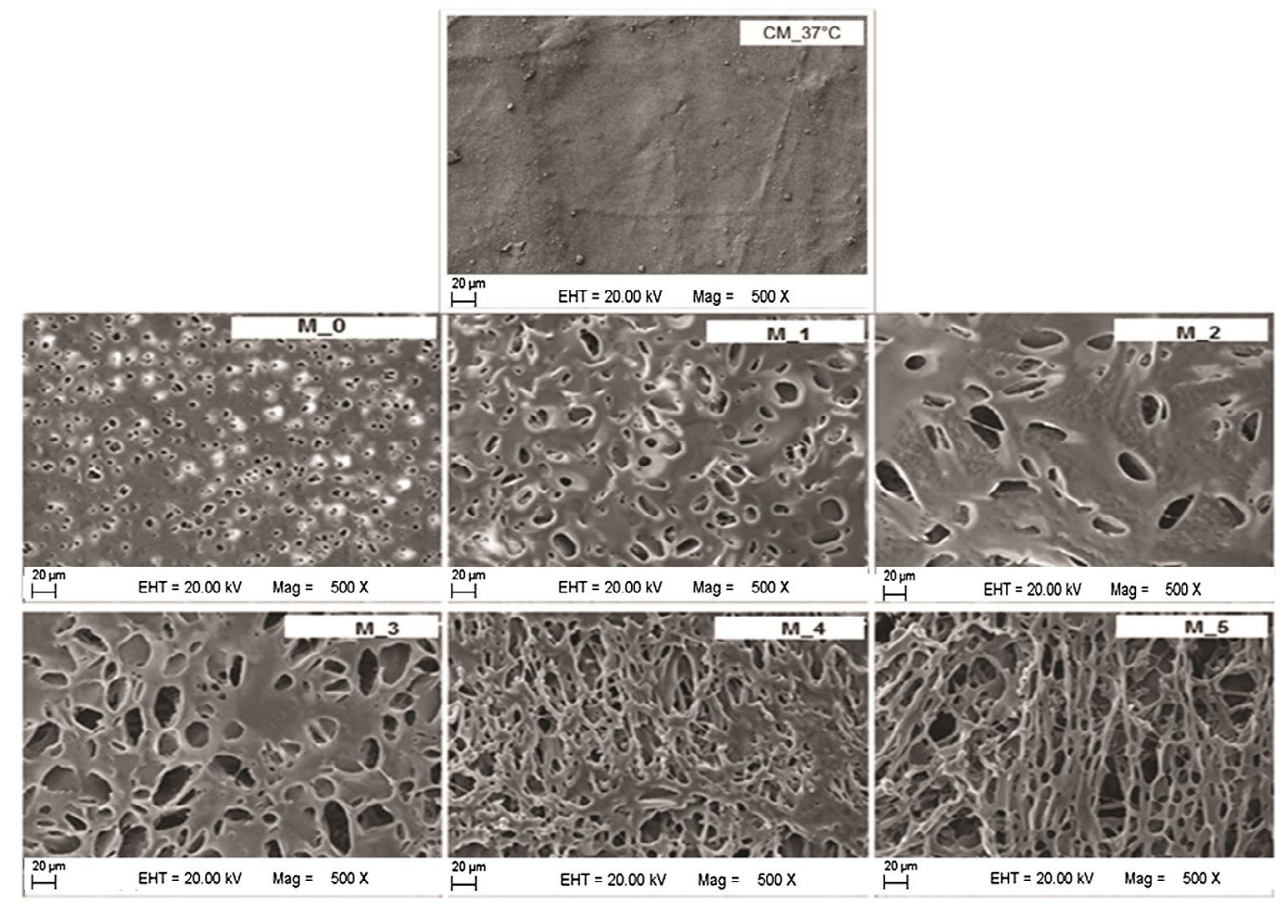

Figure 1. Micrographs of the membranes at 500x, evidencing increased porosity as the volume of water increased. 

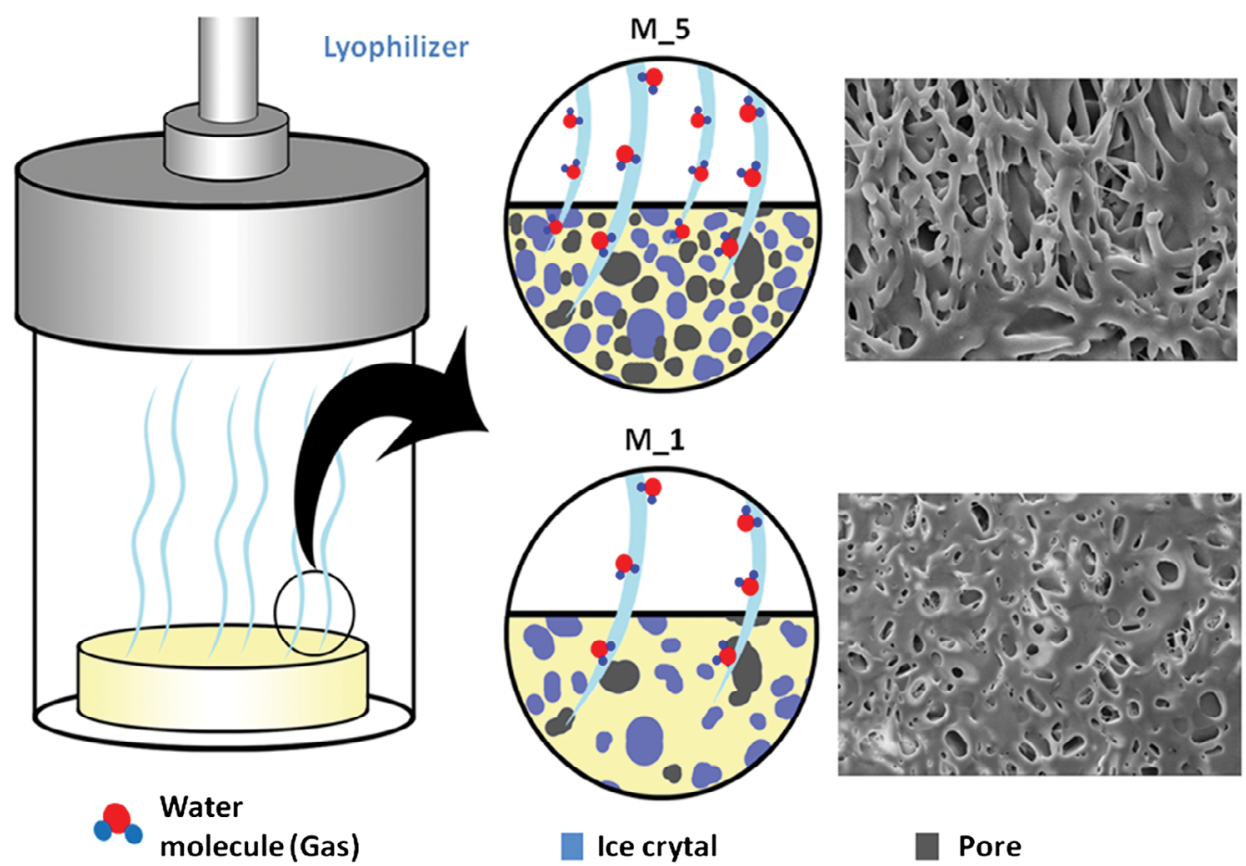

Figure 2. Method of manufacturing porous membranes using lyophilizer with different amounts of water. Note: The membrane M_5 (5:1) had highest pore size.

\subsection{Water vapour permeability}

The physicochemical properties of the different membranes were evaluated. A mass loss versus time graph (Figure 3 ) showed linear relationships for all membranes, indicating that the permeation flow of water through the membrane was constant. However, the rate of permeation increased with pore size (due to the water:latex relationship addressed above).

The WVP values are presented in Table 1 . As expected, the CM_3 ${ }^{\circ} \mathrm{C}$ showed a lower WVP value than the other freeze-dried membranes. In general, the greater the volume of water added, the higher the porosity and WVP values due to the facilitated diffusion of water molecules through the membrane structures. These results were in accordance with those presented by Pichayakorn et al. [29], who showed that a high water flux was correlated with a higher porosity for membranes obtained from deproteinized NRL and polymer blends.

It was observed that the membrane produced by the conventional method $\left(\mathrm{CM}_{-} 37^{\circ} \mathrm{C}\right)$ had no pores and therefore $0 \%$ permeability. The membrane M_1 (1:1) has higher pore density on the surface than other membranes. However, M_1 has smaller pores that lead to a decreased permeability. Membrane M_5 displays the largest porosity and thus the highest permeability.

\subsection{Mechanical properties}

The mechanical properties of the membranes are presented in Table 1. The lyophilized membranes showed PS values ranging from 1.07-1.88 MPa, and these values were lower than the value observed for the conventional membrane, $\mathrm{CM} \_37^{\circ} \mathrm{C}(2.40 \mathrm{MPa})$. Additionally, Table 




Figure 3. Permeation flow of water through the different membranes.

Table 1. Results for the water vapour permeability (WVP), puncture strength (PS) and elongation at break $\left(E_{\mathrm{b}}\right)$ of the membranes $(n=3$; mean $\pm \mathrm{SD})$.

\begin{tabular}{lccc}
\hline Membrane & WVP $\left(\mathrm{g} \mathrm{mm} / \mathrm{m}^{2} \mathrm{~h} \mathrm{kPa}\right)$ & PS $(\mathrm{MPa})$ & $E_{\mathrm{b}}(\%)$ \\
\hline CM_37 ${ }^{\circ} \mathrm{C}$ & $0.000040 \pm 0.000005$ & $2.40 \pm 0.50$ & $361.40 \pm 30.10$ \\
M_1 & $0.019500 \pm 0.007800$ & $1.88 \pm 0.24$ & $456.13 \pm 20.67$ \\
M_2 & $0.034500 \pm 0.011000$ & $1.66 \pm 0.23$ & $495.11 \pm 22.31$ \\
M_3 & $0.036700 \pm 0.005600$ & $1.47 \pm 0.25$ & $531.67 \pm 25.96$ \\
M_4 & $0.050800 \pm 0.023400$ & $1.31 \pm 0.09$ & $481.93 \pm 41.82$ \\
M_5 & $0.060600 \pm 0.017900$ & $1.07 \pm 0.07$ & $487.82 \pm 09.35$ \\
\hline
\end{tabular}

1 shows that the PS decreased with increasing porosity (water:latex ratio). M_5 presented the lowest PS, likely due to its higher porosity, weakening the membrane's mechanical resistance. The PS values obtained in this work were up to $10 \times$ greater than those reported by Pichayakorn et al. [30] (PS = 0.23 MPa) for a membrane formed from deproteinized NRL obtained from $H$. brasiliensis. This difference could be attributed to the absence of proteins in the polymer.

The $E_{\mathrm{b}}$ values showed a different behaviour: for lyophilized membranes, these values were larger than the value observed for the conventional membrane. However, the $E_{\mathrm{b}}$ values of the lyophilized membranes were similar. The PS and $E_{\mathrm{b}}$ ranges observed for the lyophilized membranes may make these membranes suitable for transdermal patch applications.

\subsection{Release assay}

To evaluate the porous effect and the application of the membranes as drug delivery systems, in vitro drug release tests were performed in deionized water using membranes $\mathrm{CM} \_37^{\circ} \mathrm{C}$, M_1, M_3, and M_5 containing BSA. The obtained release profiles are shown in Figure 4. 




Figure 4. In vitro BSA release profile for the latex membranes.

The amount of BSA released was quantified by HPLC at $220 \mathrm{~nm}$. Membrane CM_37 ${ }^{\circ} \mathrm{C}$ presented a burst release within the first $1 \mathrm{~h}$, with $43 \%$ of the total BSA released. The conventional membrane does not contain pores on its surface and thus releases absorbed molecules suddenly (burst release). This phenomenon overestimates release values at the beginning of release assays [31]. After this burst, only $6 \%$ of the BSA eluted into the solution $(0.44 \% / \mathrm{h})$ until $12 \mathrm{~h}$, with a total BSA mass release of $49 \%$. The burst release observed from the conventional membrane $\left(\mathrm{CM} \_37^{\circ} \mathrm{C}\right)$ was not observed for the porous membranes. Instead, these membranes slowly released BSA over the entire assay period. This can be due to the large number of pores, which could store the BSA inside the polymeric matrix. The release of BSA in these membranes showed two stages. The first was linear until $3 \mathrm{~h}$, with drug release of 37, 37 and 55\% for M_1, M_3 and M_5, respectively. Correspondingly, smaller initial releases were observed (due to the lower protein content on the surface) when compared with conventional latex membrane. In addition, the comparison between the membranes M_1 and M_5 showed that tuning the porosity allows control of the initial release. This controlled initial release allows that a fraction of the compound rapidly leads to the desired therapeutic concentration of the drug. Afterwards, the release decreases but continues for up to $12 \mathrm{~h}$ (maximum time of evaluation). The release after the first $3 \mathrm{~h}$ was dependent on porosity, with higher porosity correlating to higher release. The release speed was 1.4, 2.8 and 3.8\%/h for M_1, M_3 and M_5, respectively. This result shows that the release of BSA increases almost 3 times with the porosity. This drug release behaviour sustains the dose of compounds and it could enable reaching the desired drug concentration. It is important to maintain drug concentration in the blood or in target tissues for as long as possible. In these membranes, higher levels of BSA were incorporated into the inner portions due to the membranes higher porosity. The release profiles for M_1, M_3 and M_5 also showed that after $12 \mathrm{~h}, 52,64$ and $88 \%$ of the total initial BSA was released, respectively. This data shows correlation between larger porosity and higher release of the entrapped drug. 


\subsection{Haemolytic assay}

Once porous natural latex membranes are promising material to be used in biomedical applications, it is important to evaluate the influence of the porosity on their toxicity. The haemolytic activity assays of the components released by the latex membranes were evaluated based on damage to the membranes of red blood cells (NEW PROV, code: 1189, Paraná, Brazil).

The tests were conducted using $24 \mathrm{~h}$ cumulative extracts from the membranes. Under these conditions, the NRLb membranes (conventional or porous) presented no haemolytic effects, indicating no detectable effects on the red blood cell membrane (Figure 5). Red colouration of the supernatant was not observed, i.e. no haemoglobin was released, indicating that the red blood cells remained intact. These results were similar to those found by studies that used calcium phosphate $(\mathrm{Ca} / \mathrm{P})$ or oxytocin-coated natural latex membranes $[13,32]$.

\subsection{Cytotoxicity assay}

The cytotoxicity assay was performed according to ISO 10993, parts 5 and 12, by extraction of the membrane and exposure to cell cultures [33]. The presence of cytotoxic leachates was indicated by decreased cell viability. The extraction method was standardized by mass to avoid differences due to density caused by the different porosities in the membrane samples. According to ISO 10993-5 [34], a reduction in cell viability by more than $30 \%$ is considered a cytotoxic effect. At no dilution, the eluates were toxic for all samples. However, there was a significant reduction in cytotoxicity observed for M_1, M_2 and M_3. When the eluates were diluted to concentrations ranging from 40 to $80 \%$ in complete growth medium (v/v), the solutions were not cytotoxic (Figure 6).

In the work of Borges et al. [35] the results were very similar to those of this work, where the undiluted eluates (100\%) presented viability of 30 to $40 \%$. Despite our results showing toxicity of the $100 \%$ eluate, many papers analysing NRL latex membranes in vivo have shown excellent results in biocompatibility [36,37] and in tissue regeneration [6,7].

In the experiments with eluate dilutions (80,60 and 40\%) no cytotoxicity could be observed. These results indicate that the membranes could be used for biological applications, where the potentially cytotoxic compounds are released slowly and diluted in the system.

CONTROL

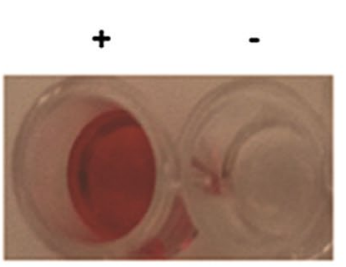

100

0

Haemolysis \%
SAMPLES



1.8
M_1

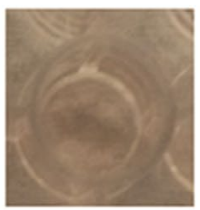

0
M_3

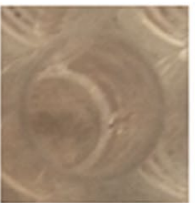

0.98
M 5

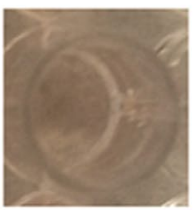

0

Haemolysis \%

Figure 5. Haemolytic activity of extracts resulting from the incubation of membranes over $24 \mathrm{~h}$. 


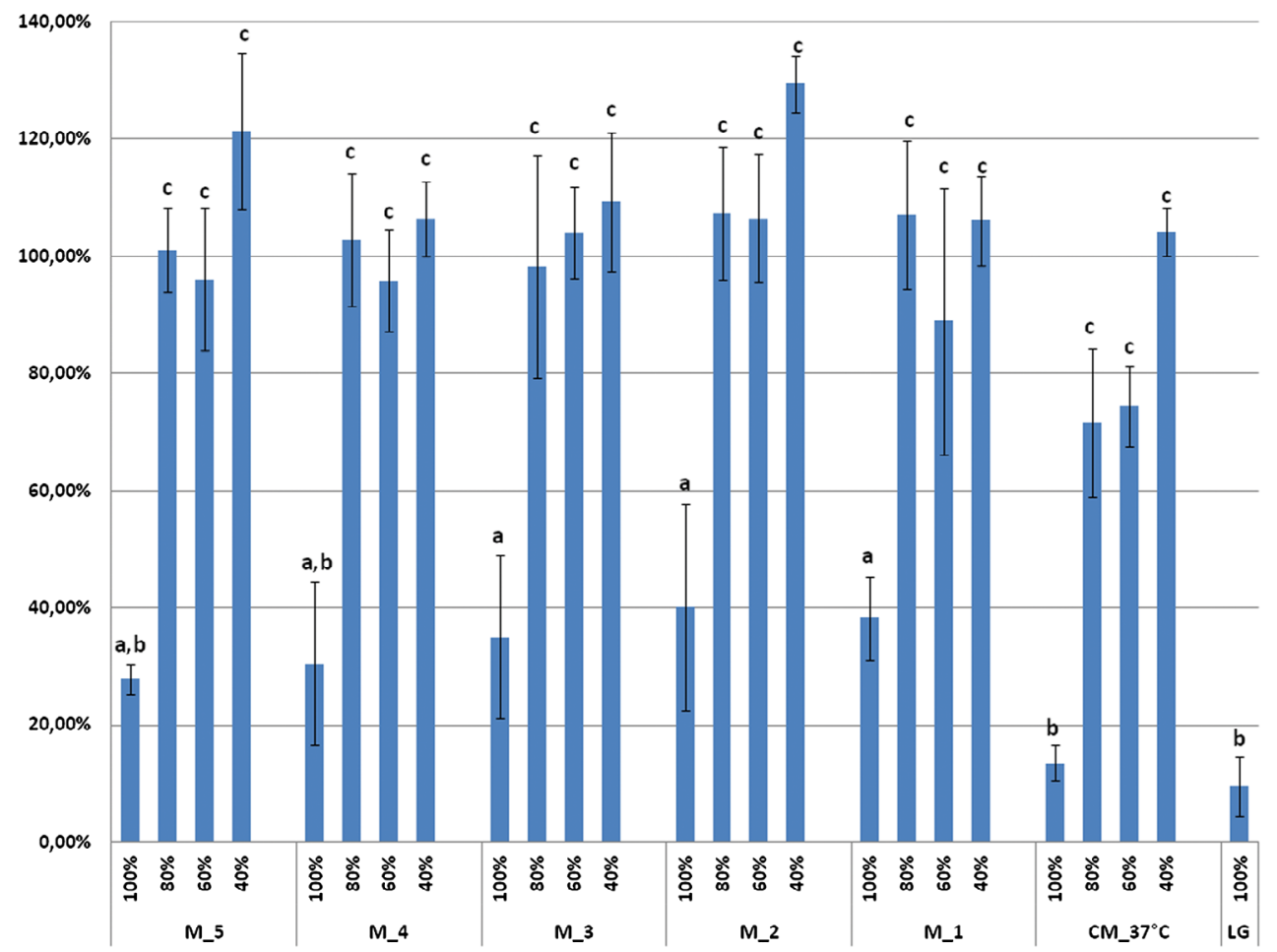

Figure 6. Cytotoxicity assay of membranes and MC3T3 cells.

Baek et al. [38] compared the cytotoxicity of solutions obtained from latex and LGs. In the present study, the LG solution presented a higher cytotoxicity than the latex solution.

Nakamura et al. [39] reported that the cytotoxicity and tissue irritancies of NRL materials were primarily due to dithiocarbamate accelerators. Furthermore, the presence of antioxidants did not show any effects. In another study, Keong et al. [40] observed no cytotoxicity in radiation-prevulcanized NRL.

In this study, the centrifugation step used to reduce latex allergens would be suitable for biomedical applications. Mrue et al. [37] observed normal tissue repair and angiogenesis when NRLb-derived membranes were applied in dogs. Almeida et al. [41] observed the same results (i.e. the same biocompatibility and angiogenesis effects) with Hancornia speciosa latex.

Our results agreed with these aforementioned studies and showed toxicity only at $100 \%$ levels of eluate. These results show that the biocompatibility of lyophilized latex membranes that slowly release latex components is comparable with that of dilute solutions.

\section{Conclusion}

In conclusion, this work proposes a simple methodology to prepare NRLb membranes from $H$. brasiliensis, which allows porosity control, based on the amount of water added to the latex dispersions before freeze-drying. The membrane WVP, mechanical strength and drug release profile were dependent on the membrane porosity. 
The release profile obtained by the porous membrane is more suited for sustained drug release, wherein an initial portion of the drug is first released and the remaining portion is subsequently slowly released to maintain and prolong a localized therapeutic dose.

The lyophilized membranes showed lower cytotoxicity and haemolytic activity than the conventionally prepared membrane, $\mathrm{CM} \_37^{\circ} \mathrm{C}$. These results indicate that the produced membranes may be used in a number of biomedical applications, such as wound dressings, modulated gas-exchange membranes, and controlled drug delivery systems.

\section{Disclosure statement}

No potential conflict of interest was reported by the authors.

\section{Funding}

This work was financially supported by Coordenação de Aperfeiçoamento de Pessoal de Nível Superior (CAPES), Conselho Nacional de Desenvolvimento Científico e Tecnológico (CNPq) [grant number 470261/2012-9] and the São Paulo Research Foundation (FAPESP) [grant number 2011/17411-8], [grant number 2012/15346-7] and [grant number 2015/02343-8].

\section{ORCID}

N. R. Barros (D) http://orcid.org/0000-0001-8689-4110

\section{References}

[1] Neves-Junior W, Ferreira M, Alves $M$, et al. Influence of fabrication process on the final properties of natural-rubber latex tubes for vascular prosthesis. Braz J Phys. 2006;36:586-591.

[2] Nawamawat K, Sakdapipanich JT, Ho CC, et al. Surface nanostructure of Hevea brasiliensis natural rubber latex particles. Colloids Surf A. 2011;390:157-166.

[3] De Pinho E. Experimental use of latex biomembrane in conjunctival reconstruction. Arquivos Brasileiros de Oftalmologia. 2004;67:27-32.

[4] Borges AF, Bolognesi LF, Trecco A, et al. Natural rubber latex: study of a novel carrier for Casearia sylvestris swartz delivery. ISRN Polym Sci. 2014;2014 Article ID 241297, 5 pages.

[5] Ereno C, Guimarães SAC, Pasetto S, et al. Latex use as an occlusive membrane for guided bone regeneration. J Biomed Mater Res Part A. 2010;95A:932-939.

[6] Frade M, Salathiel A, Mazzucato E, et al. A natural biomembrane as a new proposal for the treatment of pressure ulcers. Med Cutánea Ibero-Latino-Americana. 2006;34:133-138.

[7] Frade MC, Cursi IB, Andrade FF, et al. Management of diabetic skin wounds with a natural latex biomembrane. Med Cutánea Ibero-Latino-Americana. 2004;32(4):157-162.

[8] Herculano RD, Brunello C, Graeff C, editors. Solid state nitric oxide sensor using a latex rubber matrix. Macromol Symp. 2006;245:529-532.

[9] Herculano RD, Silva CP, Ereno C, et al. Natural rubber latex used as drug delivery system in guided bone regeneration (GBR). Mater Res. 2009;12:253-256.

[10] Kemp AR, Straitiff WG. Latex. US Patent 2,276,986. 1942 Mar 17.

[11] Araújo S. Vulcanization of induced natural rubber latex with electron beam [Master's thesis]. São Paulo: IPEN/CNEN-SP; 1993.

[12] Herculano RD, Brunello C, Graeff CFdO. Optimization of a novel nitric oxide sensor using a latex rubber matrix. J Appl Sci. 2007;7:3801-3805.

[13] de Barros NR, Miranda MCR, Borges FA, et al. Oxytocin sustained release using natural rubber latex membranes. Int J Pept Res Ther. 2016;22:435-444.

[14] Hasma H. Proteins of natural rubber latex concentrate. J Nat Rubber Res. 1992;7:102-112. 
[15] Herculano RD, Guimarães SAC, Belmonte GC, et al. Metronidazole release using natural rubber latex as matrix. Mater Res. 2010;13:57-61.

[16] Langer R, Folkman J. Polymers for the sustained release of proteins and other macromolecules. Nature. 1976;263:797-800.

[17] Akhgari A, Farahmand F, Afrasiabi Garekani HA, et al. Permeability and swelling studies on free films containing inulin in combination with different polymethacrylates aimed for colonic drug delivery. Eur J Pharm Sci. 2006;28:307-314.

[18] Prezotti FG, Meneguin AB, Evangelista RC, et al. Preparation and characterization of free films of high amylose/pectin mixtures cross-linked with sodium trimetaphosphate. Drug Dev Ind Pharm. 2012;38:1354-1359.

[19] Limmatvapirat S, Limmatvapirat C, Puttipipatkhachorn S, et al. Enhanced enteric properties and stability of shellac films through composite salts formation. Eur J Pharm Biopharm. 2007;63:690-698.

[20] Onuma Y, Satake M, Ukena T, et al. Identification of putative palytoxin as the cause of clupeotoxism. Toxicon. 1999;37:55-65.

[21] Allarcon JB, Malito M, Linde H, et al. Alergia ao látex. Rev Bras Anestesiol. 2003;53:89-96.

[22] Westall B. The molecular weight distribution of natural rubber latex. Polymer. 1968;9:243-248.

[23] Kovuttikulrangsie S, Tanaka Y. NR latex particle size and its molecular weight from young and mature hevea trees. J Rubber Res. 1999;2:150-159.

[24] Kovuttikulrangsie S, Sakdapipanich JT. The molecular weight (MW) and molecular weight distribution (MWD) of NR from different age and clone Hevea trees. J Sci Technol. 2004;27:337342.

[25] Head W, Lauter W. Ultrasonic depolymerization of natural polymers. J Am Pharm Assoc. 1957;46:617-621.

[26] Chae SY, Jang M-K, Nah J-W. Influence of molecular weight on oral absorption of water soluble chitosans. J Controlled Release. 2005;102:383-394.

[27] Lloyd DR, Kinzer KE, Tseng H. Microporous membrane formation via thermally induced phase separation. I. Solid-liquid phase separation. J Membr Sci. 1990;52:239-261.

[28] Issarayungyuen P, Nithi-Uthai N, Pichayakorn W, et al. Natural rubber latex foam loading with metronidazole. Adv Mater Res. 2014;844:490-493.

[29] Pichayakorn W, Suksaeree J, Boonme P, et al. Nicotine transdermal patches using polymeric natural rubber as the matrix controlling system: effect of polymer and plasticizer blends. J Membr Sci. 2012;411:81-90.

[30] Pichayakorn W, Suksaeree J, Boonme P, et al. Deproteinised natural rubber used as a controlling layer membrane in reservoir-type nicotine transdermal patches. Chem Eng Res Des. 2013;91:520-529.

[31] Saska S, Scarel-Caminaga RM, Teixeira LN, et al. Characterization and in vitro evaluation of bacterial cellulose membranes functionalized with osteogenic growth peptide for bone tissue engineering. J Mater Sci: Mater Med. 2012;23:2253-2266.

[32] Borges FA, Filho EA, Miranda MCR, et al. Natural rubber latex coated with calcium phosphate for biomedical application. J Biomater Sci Polym Ed. 2015;26:1256-1268.

[33] ISO. Biological evaluation of medical devices. V. Tests for cytotoxicity: in vitro methods; Geneva, Switzerland: International Organization for Standardization, 2009; 10993-10995.

[34] ISO. Biological evaluation of medical devices. Part 12. Sample preparation and reference materials; Geneva, Switzerland: International Organization for Standardization, 2012;10993-12.

[35] Borges FA, de Barros NR, Garms BC, et al. Application of natural rubber latex as scaffold for osteoblast to guided bone regeneration. J Appl Polym Sci. 2017;134:45321-45331.

[36] Floriano JF, da Mota LSLS, Furtado EL, et al. Biocompatibility studies of natural rubber latex from different tree clones and collection methods. J Mater Sci: Mater Med. 2014;25:461-470.

[37] Mrue F, Netto JC, Ceneviva R, et al. Evaluation of the biocompatibility of a new biomembrane. Mater Res. 2004;7:277-283.

[38] Baek HS, Yoo JY, Rah DK, et al. Evaluation of the extraction method for the cytotoxicity testing of latex gloves. Yonsei Med J. 2005;46:579-583. 
[39] Nakamura A, Ikarashi Y, Tsuchiya T, et al. Correlations among chemical constituents, cytotoxicities and tissue responses: in the case of natural rubber latex materials. Biomaterials. 1990;11:92-94.

[40] Keong C, Zin WW, Ibrahim P, et al. Radiation prevulcanized natural rubber latex: cytotoxicity and safety evaluation on animal. IOP Conference Series: Materials Science and Engineering. 2010;11:12002-12007.

[41] Almeida LM, Floriano JF, Ribeiro TP, et al. Hancornia speciosa latex for biomedical applications: physical and chemical properties, biocompatibility assessment and angiogenic activity. J Mater Sci: Mater Med. 2014;25:2153-2162. 